\title{
Participatory Cultures and Participatory Public Space
}

\section{Scott McQuire}

I

I often ride to work through a large park in inner-city

Melbourne. It's a longer route but more peaceful, as it gets me off the overcrowded roads. At one point, there is a dirt trail about fifty metres long that I use to traverse the space between two paved paths. It's an example of what architects call 'desire lines'-user-created pathways where formal ones don't exist, or don't fit the inhabitants' preferred patterns of use. We see desire lines in cities all the time, particularly in the kind of abandoned or undefined sites Nikos Papastergiadis calls 'parafunctional' spaces. ${ }^{1}$

What interests me about this particular path is, first, that it's a collectively made artefact existing in public space. Second, that it is not static but has shifted over time. As a small tree near one junction has grown, it has gradually come to obstruct the path. As a result, riders gradually began to veer a bit wider at this point. For a time - in fact a period of several months - there were two distinct paths. Now, the original path has become impossible to use and only a faint trace remains.

Both the formation of the path and the process of its realignment are worth considering in the context of what I'm calling 'participatory public space'. They offer a model of selforganised, collective action undertaken by a dispersed group who don't know each other personally and, in fact, have never met together in person. The dirt path has come into being because different riders have decided to take a short-cut; over time the path inscribed by their wheels signals the possibility of a different route to others, who in turn reinforce it by riding it. This process of collective attunement is foregrounded in 
the alteration of the path's trajectory. No one was formally charged with making a decision about changing the path's alignment. Rather, different users collectively responded over time to changes in the environment, spurred by a desire to keep the route's amenity while respecting the growth of the tree. It's the kind of simple action that occurs commonly. Yet it shouldn't be simply passed over. This supple, collectively produced alteration to the path stands in marked contrast to the likely situation if this was an official, paved - and therefore fixed - path that needed modification. Once the problem of an obstruction was identified, someone would probably have been charged with cutting off the offending branch. It's quite possible they would simply cut the whole tree down. Either way, it is likely it would have taken thousands of dollars to formulate, plan and complete the job. Instead, a better result has been achieved for 'free' by a distributed form of collective public action.

II

In one of his early essays on urban space Guy Debord advocated putting switches on streetlights. It's a suggestion I love, not so much for its practicality, but for its capacity to provoke us to rethink how much we take it for granted that large swathes of our public environment remain outside our control. Perhaps this is a good thing with street lighting. But there are many other areas where we don't seem to have the balance right between top-down and bottom-up action.

In a famous essay first published in 1968, Henri Lefebvre addressed the urban question in terms of what was dubbed the 'right to the city'. ${ }^{2}$ For Lefebvre the right to the city is not about extending the purview of representative government, nor about codifying urban space in terms of formal rules and obligations, but concerns the right to participate in and collectively shape the environment we inhabit. Contrary to the top-down ethos of centralised planning and governance that had dominated modern urbanism, Lefebvre argued that the capacity for a city's inhabitants to actively appropriate the time and space of their surroundings was a critical dimension of modern democracy. Lefebvre's thought has been immensely influential, and some of his concepts, including 
the contention that all space is socially produced space, have become almost axiomatic in contemporary urban planning. However, this is not to say that all the lessons of his distinctive blend of Marxism and a critical phenomenology of everyday life have been fully understood or embraced. Recently, prominent Marxist social theorist David Harvey revisited Lefebvre's concept of the right to the city, arguing that it 'remained one of the most precious yet most neglected of our human rights'. ${ }^{3}$

In this chapter, I want to begin to redress this neglect, approaching it from a particular point of view by considering the role of media art in producing a more participatory public space. This involves two related steps. First, I want to repose Lefebvre's concept in the context of the networked city. How should we think the right to the networked city, the city of ubiquitous information access, of context-aware data, pervasive sensor systems, and the like? Second, I want to consider the role artists might play in helping reimagine the right to the networked city, broadening it from the frequently narrow and often frightening visions of an instrumentally oriented 'smart city' that have become an all too common urban future.

Of course, 'participatory public space' has a ring of tautology to it: after all, as the pin-up example of collectively produced media, Wikipedia, reminds us, public space is defined by the fact that is 'open and accessible to all citizens'. But this ideal has rarely, if ever, been realised in practice. As Lefebvre's formulation reminds us, public space is a striated, contested zone of action with both visible and invisible barriers. Participation in public space has always had to be thought on a variety of levels, from formal laws regulating access and behaviour to decisions made in the realm of architecture and urban design that establish physical parameters to the way the capacities of individual subjects are shaped by socioeconomic distinctions and cultural protocols. All these factors combine to influence a person's sense of belonging or not belonging in a public space, impacting on their confidence to occupy and act in particular spaces, or, conversely, to avoid them, and to withdraw from social engagement.

In the twenty-first century we need to add the impact of digital networks to this mix. Digital communication infrastructure exerts a growing salience on public space, shaping 
not only its ambiance but its social dynamics. This has been driven by two key changes in contemporary media:

1. The diversity of sites in which media can now be accessed, as a range of embedded and mobile platforms supplement the older urban media geography based on relatively limited fixed sites of access.

2. The growing utilisation of place sensitive content and context-aware applications enabled by common incorporation of GPS systems

These changes underpin the emergence of new practices of urban communication and have become increasingly important to the exercise of social agency in public - for instance, the capacity to decipher and navigate the city, to organise, and to act, alone or in concert with others. It's from this perspective that I want to pose the question of participatory public space precisely at the intersection of urban space and media space, where we witness the increasing and ambivalent imbrication of social life with complex technical networks. How does this transform the older and better-known powergeometries of the city, force-lines named in terms of class, gender and sexuality, race and ethnicity? Is the composition of public culture becoming more differentiated and complex? Are there new emergent possibilities for participation? Or are old stratifications being further consolidated?

\section{III}

In addressing such questions here, I will argue that artists can play a key role, not as de facto sociologists or anthropologists, but by initiating modes of practice that take networked public space as the site for enacting experimental forms of communication and cooperation. Over the last decade and a half artists and activists have frequently challenged dominant uses of digital networks, by problematising the default settings of spectacle and surveillance, and by inventing new protocols, interfaces and alignments of technologies, spaces and bodies. This has been part of a broader shift in thinking about art: a move away from the paradigm of re-presentation, in which 
the art work is always a belated response to a social situation, to a new paradigm in which art can play a role in intervening in ongoing social dynamics. This is not to reduce art to a tool for social engineering but to recognise the capacity for art to generate complex models of communication and interaction that are not easily reduced to the classical cybernetic yardstick of efficient transmission. It's in this sense that I read Maurizzio Lazzarato's injunction: 'artists could be seen as communication experts; but this depends less on connections to the patrons than to publics: not so much pop contests but producing work which matters to people'. ${ }^{4}$

There is a particular urgency in exploring these issues in the Australian context, following the federal government's commitment of up to $\$ 37$ billion of public funding to the construction of a high-speed national broadband network $(\mathrm{NBN})$. As the network has been designed and roll-out begins, it has become the site for numerous arguments concerning cost, model of funding, likely economic impact and so on. Disturbingly few contributions to these public debates come from a cultural perspective, so there has been little thought about how the different models of network architecture, access and governance might contribute to or detract from a richer, more inclusive public culture, one in which the right to the city can be exercised more fully. One of my starting points is to acknowledge that public culture is constantly being reinvented, for better and for worse. A key lesson from Richard Sennett's seminal book The Fall of Public Man is not so much his rather pessimistic account of social life in contemporary cities, but his demonstration of the historical mutability of public life, and his insistence that public sociability is not natural but learned. ${ }^{5}$ Civility, as the modern replacement for feudal bonds built around obligation and deference, is a complex social relation that needs to be experimented with, practiced, and nurtured. It's a theme Sennett returns to in his most recent book, where he argues that complex societies such as those engendered in modern cities require novel forms of social cooperation: 'a demanding and difficult kind of cooperation [that] tries to join people who have separate or conflicting interests, who do not feel good about each other, who are unequal, or who simply do not understand each other' ${ }^{6}$ 
If, as Simmel established a century ago, the existential quandary of the modern city is how to develop and sustain a social relation to strangers, Sennett reposes this as the challenge 'to respond to others on their own terms'.7 A critical element of Sennett's argument-and one that brings the issue of how contemporary art might activate public space to the fore - is that responding to this challenge is not just a question of ethical attitude, but is something that requires social skill. For Sennett, skill 'emerges from practical activity'. Taking action develops capacities in different ways from purely intellectual responses, shifting understanding from the sometimes restrictive terrain of normative ideals to the more varied and fluid experience of negotiation and collaboration, assertion and deference, where capacity to listen has to be balanced with willingness to speak, and the desire to find common ground exists in an unstable equilibrium with the need to assert points of difference. Art is at home in these kinds of endeavours. Insofar as it opens a space of questioning, doubt and ambiguity, art can not only sketch new models for being together in public, giving an experimental shape to social encounters, but it can also enable individuals to hone cooperative skills through the performative enactment of new forms of social collaboration.

IV

While there's a long and varied history of participatory art, today participation has become a buzzword, much like 'interactivity' was in the 1990 . Moreover, this flavour has spread much wider than the media/internet sector where its most recent incarnation emerged. In the wake of Tim O'Reilly's influential branding of Web 2.0, we read not only of participatory media and participatory culture, but also participatory education, participatory planning, participatory medicine, participatory urbanism and even participatory business. And of course, that great non sequitur, participatory government! It's in this context that 'participatory art' has become a default policy: almost everybody thinks it's a good thing, but there has been relatively little sustained interrogation of what is meant by 'participation'.

One of the pressing questions for the development of 
participatory public space is how we might use the sort of principles demonstrated by peer-to-peer (P2P) networks in the broader context of the city. As Benkler argues:

What characterises the networked information economy is that decentralised individual actions - specifically, new and important cooperative and coordinate action carried out through radically distributed, nonmarket mechanisms that do not depend on proprietary strategies - play a much greater role than it did, or could have in the industrial information economy. 8

These non-market forms have always existed, but were progressively downgraded in the era of industrial capitalism, predicated on the formative enclosure of the commons and the gradual subjection of more and more areas of social life to the dictates of the market. For Benkler and numerous other analysts, the internet is a game-changer: provision of wider access to low cost communication infrastructure enables the scalar extension of what Benkler calls peer-based commons production to more and more areas, from software to other informational goods and, potentially, beyond. Michel Bauwens elevates this into the potential for evolving a postcapitalist mode of resource allocation and production, seeing in P2P networks the model for a sophisticated and supple social process specifically designed to engender the most widespread participation by equipotential participants. ${ }^{9}$ There are a number of assumptions embedded in such an argument. First, Levy's notion of 'collective intelligence': the idea that no one knows everything, but everyone knows something, which underpins contemporary practices of crowd-sourced production. Second, while Bauwens acknowledges that P2P systems are not without hierarchy (and this is an area of urgent research), he contends that such structures are more flexible, based on distributed authority and the principle of encouraging the widest possible participation. If this has the flavour of Marx's 'from each according to his means, to each according to his needs' of communism, Bauwens argues against equating $\mathrm{P} 2 \mathrm{P}$ production with the 'primitive' communism of an older 'gift economy'. Unlike the social reciprocity of tribal societies, 
or the practice of equality matching (repaying individual debts to particular participants), P2P exchanges are conditioned by the scale and complexity of contemporary social life which establishes mutual anonymity as the basis for many social interactions. In this context, abstract systems of trust (such as expert accreditation) and exchange (money, credit) dominate social life. If there is a mode of gift-giving in contemporary $\mathrm{P} 2 \mathrm{P}$ exchanges, such as the donation of intellectual labour to software projects, it usually follows a non-reciprocal pathway, in which the gifts are widely distributed in space and time, and any 'returns' are more likely to accrue to others than to the individuals who initiated the exchange.

How might we translate these principles into a networked public environment? How can we develop non-market forms of collaborative interaction that utilise digital networks in order to reconfigure public space by both imagining and enacting new possible models of being in public? Does the random and relatively anonymous contributions of $\mathrm{P} 2 \mathrm{P}$ production resemble the collective and loosely coordinated action of bike riders altering the alignment of a desire line in a park with which I began this chapter? No one owns the outcome, no single person could produce it without enormous effort, yet all benefit from the intervention. Can digital art in public space support such loosely coordinated, cooperative action between strangers?

\section{V}

In order to advance this discussion, I want to offer three examples of work that operates in this space. Over the last twenty years Rafael Lozano-Hemmer has become renowned for his large-scale interactive public art works. He often deploys innovative interfaces, making alternative use of tracking systems and biometric data to enable multiple inputs to a dynamic work. In this regard, Lozano-Hemmer's work offers a signal example of how an artwork might be conceived as a platform capable of sustaining a variety of modes of public participation. Works such as Body Movies (2001) are distinctive in allowing for both individual and collective participation, in providing avenues for both physically active and contemplative engagement, and in the way they encourage inventive, 
playful choreographies to develop between strangers gathered in public space.

The work I want to focus on here is Vectorial Elevation (2010), which was recently reprised for the Vancouver Olympic Games. ${ }^{10}$ Vectorial Elevation is a work involving a battery of powerful remote-controlled searchlights accessed by members of the public, who can design and initiate temporary light patterns through a web interface. It was first staged in the massive Zocalo Plaza in Mexico City in 200o. Vectorial Elevation stands in relation to a long line of 'light architecture' spectacles, which have historically been designed with the aim of exerting maximum impact on the 'masses'. The most infamous example is Albert Speer's 'cathedral of light' created as the context for one of Hitler's rallies. But we could also connect this line to contemporary urban light spectacles, such as the coordinated light shows that animate the Hong Kong skyline nightly as the city's dense network of towers collectively display their LED plumage. Vectorial Elevation sought to challenge the centrally controlled nature of such spectacles by using the internet as mechanism for providing public access. In a sense, it took Debord's injunction about putting switches on streetlights literally, and uses network technology to put multiple users' hands on the switch, redistributing social agency in public space. This capacity to enable users to participate in the construction of temporary ambiances on a large scale in the city centre is an important innovation that should not be taken lightly. In Lozano-Hemmer's words: 'I tried to introduce interactivity to transform intimidation into intimacy.' 11

Distributed control over public lighting certainly disrupts the traditional logic of the urban light show, and it undoubtedly produces a more varied pattern than an 'official' choreography would. But, rather than intimacy, I suspect most visitors to Zocalo Plaza still experienced the work primarily as a spectacle-something they watched with a feeling of awe rather than a strong sense of ownership or control. However, there was another level of participation to the project that it is important to mention: the webpages which archived each design. I'll quote what Rafael told me about the process in 2006: 
The web pages for Vectorial Elevation were created automatically for every participant and the comments field was there so that people could personalise their design with dedications, poems, political statements, etc. Those comments fields were completely uncensored, which was quite a feat at the time because the Zapatistas were quite active electronically at that time ... I convinced the politicians that if we censored that then the piece would become only about censorship and that they needed to stop having a paternalistic and condescending view of the general public and trust that they will send interesting texts. Sure enough we had many Zapatista messages (thank goodness for that!) but also marriage proposals, soccer scores, etc. The point being that those comments were an important aspect in the takeover of a public space. ${ }^{12}$

This comment underlines the need for situated analyses of particular interfaces and art works: what succeeds in one context cannot necessarily be translated to others. Vectorial Elevation assumed a marked political charge in the context of Mexico City, where, among other things, it provided a platform for unconstrained public dialogue that was otherwise hard to find at the time. When Vectorial Elevation was repeated in Vancouver, there were a number of modifications, both to the web interface and the way people could participate on site. The website for the Vancouver project reveals the expanded scale of public participation measured in raw number of users, and the work undoubtedly remains an innovative exercise in the collective construction of an ephemeral intervention in a city centre public space. User comments archived in the website reveal the pleasure and the sense of agency that many people experienced when witnessing their own design come to fruition and be projected across the city. However, the more critical political edge of the work relating to the open comment field was undeniably - and understandably-less sharp in Vancouver 2010.

It's also worth noting a tension running through this work, which is pertinent to many similar projects. While designed as a 'platform for participation', Vectorial Elevation depends on an expensive and complex technological system that 
remains quite closed in some respects. Despite the ambition to encourage participation and agency from the audience, conceptualisation and construction of the platform takes place largely in their absence, lending a 'black box' element to the work. Lozano-Hemmer is clearly aware of the issue, insofar he regularly includes mechanisms for participants to become aware of how the work is constructed. These mechanisms go beyond documentation of design and technical systems to introduce performative elements that 'reveal' the system at work (such as the regular resetting of the system in Underscan so that participants find themselves inside a projected light grid, which is how the tracking system used in the work 'sees' the interaction space). Addressing this tension is a key challenge for contemporary artists using digital media: how to use complex technological interfaces in ways that enable open forms of social interaction, while also expanding public input into the design and formation of the systems themselves.

The second example I want to discuss in this context is Blast Theory's Rider Spoke, which was staged in Sydney and in Adelaide in 2007. ${ }^{13}$ Rider Spoke belongs to the genre of locative media art concerned with annotating physical places with geolocated information. Like other works by Blast Theory, Rider Spoke is an open-ended urban game that uses narrative to form an ambulatory artwork. Equipped with a headset and on-cycle computer, participant-cyclists are asked to explore the city. The narrator provides them with cues to seek out certain sorts of places where they are invited to make personal responses to their surroundings and to the narrator's prompts. What is distinctive about the work is the way the responses are then tagged to specific places. Participants can use the customised screen interface to navigate to 'hiding places' where other participants have left their own comments and responses, which can only be heard by someone actually occupying those places.

The work's combination of open-ended movement through the city in conjunction with exploration of participants' emotional and psychic terrain - memories, observations of those around them, reflections on important occasions or emotions - proved highly evocative. While it is a highly individualised work - riders take their journey alone and 
the prompts invite personal reflection - it doesn't simply construct a tele-cocoon. Rather than using technology to erect a shield between the user and those around them, thereby privileging communication with familiar others over encounters with proximate strangers, Rider Spoke works to create a mesh of relationships over time. How do you respond to someone recounting an intimate experience, or the admission that they feel lonely or vulnerable? Do you offer up your own story or make your own confession? Do you make something up?

At bottom, Rider Spoke is a work about trust and intimacy in the digital era. It does not depend on the sort of public confession and strip-mining of intimacy that is the currency of so-called 'reality TV' but operates in a harder to define space somewhere in between personal reverie and public civility. Each story is a 'donation', a gift of experience, but it is not offered to a particular listener. Donations are archived in a database that can only be accessed by participants when they visit that particular location. Here technology enables the distributed coordination of collective actions that combine to alter the social experience of the city, producing an experience of what might be called ambient intimacy, akin to the feeling of identification you might get from immersion in a novel, yet different because the 'content' is contributed by particular strangers inhabiting the city around you.

The final example I want to use is some collaborative research I've been involved in using large video screens as an interface for public communication. Of course, large screens tend to be predominantly associated with advertising, or with televising major live events such as sport. However, since the early 2000s, a growing number of screens located in traditional public spaces such as plazas and city squares have been exploring possibilities for more varied programming. In this context we proposed a project to explore the possibilities for using screen infrastructure to construct a temporary and experimental 'transnational public sphere'. ${ }^{14}$ What might this mean? Like the publicly situated video screen itself, the project stands at the junction of two ideas of the public sphere: the traditional public sphere rooted in immediate social interactions taking place in physical space, and the modern conception of the public sphere as primarily constituted by a more abstract 
media space. In fact, the opposition between immediate and mediated relations should not be pushed too far, as media platforms have always had distinct material geographies while relations of immediacy have equally depended on symbolic resources, notably language, that cannot be reduced to simple distinctions between presence and absence. Nevertheless, it was notable in the 1980 os and 1990 os that the emergence of digital networks was understood primarily in terms of their dislocation from, and opposition to, 'real' places and social relations. It is precisely this sense of separation between 'virtual' and 'real' that has been increasingly undermined by the development of the pervasive networks of embedded and mobile media that now dominate urban experience. Using large video screens as the interface for live events taking place simultaneously in different cities offers a strategic avenue for exploring the new contours of the experience of 'being together' in networked cities.

In August 2009 we participated in an event linking large video screens in Melbourne's Federation Square and Tomorrow City in Incheon, Korea. The event involved a combination of live camera crosses, screenings of artists' videos, and live performance in each site. It also involved two interactive art works specifically commissioned for the research, both using text messaging as the interface enabling audiences present at the event to generate content displayed simultaneously on the screens in each city. SMS_origins (created by Australian artists Leon Cmielewski and Josephine Starrs in conjunction with programmer Adam Hinshaw) invited participants to send a text message with the details of the places of birth of their parents and themselves. On receiving the message, software translates the information into lines connecting the different places on a world map displayed on the two screens. Audiences in both sites could see the creation of a real time map tracing coordinates that reflect the collective input of all participants. The graphic design of the work is deliberately simple, emphasising the process of audience input rather than offering a rich palette for personal expression. Like other crowd-sourced participatory art, the content of the work will be different each time it is displayed, depending on the composition of the audience. 
The second interactive work, Value@ Tomorrow City (created by Korean artist Seung Joon Choi) used the screen more as a public bulletin board. Audiences were asked to respond to the question: 'As a member of the future city, what do you think is the most important value?' When messages were sent, the different 'values' appeared on the screen as key words. If the words entered by one person were identical or similar to those used by others, the size and position of display changed. By using the screens as the means to display a live 'folksonomy' (an informal taxonomy generated by users), users were able to conjugate a novel form of dialogue between the inhabitants of different cities.

These two works were designed as prototypes to explore the still largely untapped potential for utilising the infrastructure of public screen for different ends from advertising display, or coverage of major live events such as professional sport. As Crang and Graham note, 'the environment has always been recursively influenced by action. What these technologies do is change the temporality of that action.'15 Real time interactivity can be manifested in many different ways. An important aspect of the design of these text-message based artworks was their capacity to display data in a manner which did not 'average' it, but retained traces of individual inputs while displaying each contribution as part of a dynamic network. ${ }^{16}$

Capacity to register, process and display in real time data gathered from a multiplicity of sources is a direct outgrowth of access to low cost, pervasive digital networks. Our initial research indicated that audience members not only gained pleasure from participation, but also developed a sense of 'connection' to those in the other city. The pleasure might be partly because the capacity to 'make a mark' in central city public spaces is relatively rare, especially for young people. Using the large screen in this way enhances a sense of belonging in the space, and also a sense of engagement with others who are watching or performing the same activity. This finding resonates with what other operators of large video screens situated in public space, such as CASZ and the BBC, have learned about the importance of local relevance to the programming of public screens. ${ }^{17}$ The sense of 'connection' 
generated between participants in different cities remains both harder to define and more important to explore. It points to the new contours of experience, an emergent psychogeography in which relations of immediacy and mediation are increasingly intertwined, and in which infrastructure such as large screens situated in public spaces might support new forms of citizen-to-citizen dialogue in public spaces which are both locally embedded and transnationally extended.

VI

Francois Truffaut's wonderful film adaptation of Ray Bradbury's novel Fahrenheit 451 offers a powerful satire of the claims of an earlier era of participatory media. In one scene, Montag (the fireman charged with burning books) watches with disdain as his wife Linda takes part in a wall-screen 'tele-play' with a part written 'just for her'. In fact the role involves Linda responding on cue and according to script, no doubt in concert with an audience of equally sedated peers. Truffaut's target was the pseudo-inclusive format of television with its fiction of direct and intimate address to each viewer - what Eco once called 'neo-television'. 18 Truffaut's point is not only that such forms of address mask a one-way communicative flow, but also that the highly scripted roles leave even the presenters with very little room for manoeuvre. It is tempting to believe that the different architecture of the internet changes everything, but the situation is clearly more complex. The integration of 'audience participation' into contemporary television, as text messages and audience voting systems merge ratings strategies with revenue generation, demonstrates that we have not yet moved as far from Truffaut's scenario of pseudo-participation as we might think. In Stiegler's formulation, the digital is the threshold of hyperindustrialisation in which production and consumption are directly articulated with credit systems

With the advent of very advanced control technologies emerging from digitalisation, and converging in a computational system of globally integrated production and consumption, new cultural, editing and programming industries then appeared. What is new is that they are 
technologically linked by universal digital equivalence (the binary system) to telecommunications systems and to computers, and, through this, directly articulated with logistical and production systems (barcodes and credit cards enabling the tracing of products and consumers), all of which constitutes the hyper-industrial epoch strictly speaking, dominated by the categorisation of hyper-segmented 'targets' ("surgically" precise marketing organising consumption) and by functioning in real time (production), through lean production [flux tendus] and just in time (logistics). ${ }^{19}$

Eco himself offered a more optimistic sense of the participatory possibilities of art in his seminal 'Open Work' essay, written in $1962 .{ }^{20}$ While Eco always acknowledges the ability for all artworks to contain multiple meanings and to thereby be interpreted differently by different readers/viewers - this was the thrust of his whole semiotic project - the essay identifies the emergence of what he calls 'works in motion'. Eco was referring to key modernist avant-garde works by artists such as Stockhausen and Brecht, in which elements were deliberately left open, either to audience input or to chance. But we can transpose Eco's concept to the present, and recognise qualities of the digital art works described above: essentially unfinished works, built around the capacity for rapidly assembling multiple inputs from various sources. The widespread availability of digital tools and the extensive networked infrastructure of contemporary cities has not only created the conditions for hyper-industrialisation, but has generated new possibilities for creating 'open works' in public space, works which vary in each different iteration, depending on the composition of users. Such works suggest models for the way digital infrastructure might be deployed as platforms for public participation.

The divergence between Stiegler's and Eco's scenarios indicates the ambivalence surrounding the issue of participatory public space that I posed at the opening of this chapter. Numerous questions remain unresolved around how digital art might be deployed as platforms for public participation capable of fostering the social skills of cooperation and 
communication that are vital to complex societies. If we follow Lazzarato ${ }^{21}$ and accept that widespread participation is an important aim for contemporary art, how do we ensure this is not equated with the dictatorship of 'easy' forms of reception: the normalisation of the idea that art should be quickly intelligible and easily digested by everyone? And how do we avoid the goal that encouraging participation might carry with it an unspoken aim of imposing a false image of social unity? As Lefebvre's concept of the right to the city attests, democracy is a process of contestation as much as consensus, and the critical role of public space as an arena for staging dissensus should not be foreclosed. If contestation should not be reduced to competition, or regulation by the invisible hand of the market, opposing this trajectory cannot be simply a matter of advocating an abstract and principled solidarity. What is significant about the works I have described here is not only their concern with the specific materiality and inscription of living bodies as elements of complex socio-technical networks but also their concern for how bodies enter into public relations. Public space in the twenty-first-century networked city has become a vital medium for exploring civility in a supernational context, and for enacting experiences and developing skills that have become integral to the challenge to extend forms of cooperation beyond the historical bounds that have hitherto defined the social.

\section{Notes}

N. Papastergiadis and H. Rogers,'The Parafunctional' in The Dream of Urbanity, ed. J. Stathatos (London: Academy Group, 1996), 76-86.

H. Lefebvre, 'The right to the city', in Writings on Cities: Henri Lefebvre, eds

E. Kofman and E. Lebas (Blackwell, Oxford and Cambridge, Mass., 1996 (originally published as Le Droit à la ville, 1968)).

3 D. Harvey, 'The right to the city', New Left Review 53 (2008): 23-40.

4 M. Lazzarato, The Misfortunes of the 'Artistic Critique' and of Cultural Employment, 2007: <http://eipcp.net/transversal/o207/lazzarato/en>.

5 R. Sennett, The Fall of Public Man: On the Social Psychology of Capitalism (New York: Vintage Books, 1978)

6 R. Sennett, Together: The Rituals, Pleasures and Politics of Cooperation (New Haven: Yale University Press, 2012).

7 Ibid., 6.

8 Y. Benkler, The Wealth of Networks (Yale University Press, New Haven, 2006), 3.

9 M. Bauwens, 'The Political economy of peer production', $2005<$ www.ctheory.net/ articles. aspx?id=499>. 
10 See <http://www.vectorialvancouver.net/home.html>.

11 R. Lozano-Hemmer, email to the author, 2006.

12 Ibid.

13 See <http://www.youtube.com/watch?v=jyI78ZFo--Y>.

14 'Large screens and the transnational public sphere' (2009-2013) is a Linkage Project funded by the Australian Research Council with partners Federation Square, Australia Council for the Arts and Art Centre Nab (Seoul).

15 M. Crang and S. Graham, 'Sentient cities', Information, Communication and Society 10, no. 6 (2007): 789-817, 811.

16 In SMS_Origins, when each mapping first appears, it is identified by the three place names and the line linking them is traced in bold. As the next mapping proceeds, the first line becomes part of the network. In Value@Tomorrow City, each term is tagged with the last digits of the sender's phone number.

17 S. McQuire, M. Martin and S. Niederer eds, Urban Screens Reader (Amsterdam: Institute of Network Cultures, 2009).

18 U. Eco, 'A guide to neo-television', Framework 25 (1984).

19 B. Steigler, The Decadence of Industrial Democracies, trans. D. Ross and S. Arnold (Cambridge: Polity Press, 2011), 5.

20 U. Eco, The Open Work, trans. A. Cancogni (Cambridge, Mass: Harvard University Press,1989).

21 Lazzarato. 